\title{
JUVENTUD DE LOS 90: UNA REFLEXION EN TORNO A LA JUVENTUD URBANO POPULAR*
}

\author{
CALETA SUR $^{* *}$
}

\section{PRESENTACIÓN}

EL PRESENTE DOCUMENTO CONSTITUYE un proceso de reflexión sobre el quehacer socio-comunitario en el cual estamos insertos y considera de manera privilegiada a las organizaciones y jóvenes que en ellas participan, son el resultado de reflexiones compartidas, de inquietudes, preguntas, rabias y esperanzas incubadas en conjunto.

Por tal razón, consideramos que el período histórico-político y sociocultural en el cual se enmarca el fenómeno juvenil, nos permite establecer y consignar no tan sólo las carencias de él sino, también, la crisis como oportunidad para la creación. Cuando nada está determinado, todo puede ser re-significado. Así, el sentido y la identidad se configuran como dos de las principales dimensiones en las que la(s) juventud(es) se ven enfrentadas, crear sentido y crear identidad, bus-

* Documento colectivo de reflexión interna de la ONG Caleta Sur, el que constituye una mirada desde el quehacer cotidiano con jóvenes en diversas poblaciones de la zona sur de Santiago, donde trabajan de manera sistemática a nivel de articulación social, prevención de drogas y defensa de derechos vulnerados.

** Documento elaborado por Mónica Bonnefoy, Oscar González y Antonio Favreau. E-Mail: caletasur@123.cl. 
car la direccionalidad de las acciones conducentes a configurar nuevos escenarios de poder, centrados en relaciones dialógicas y generadoras de dinámicas sociales creativas, no coercitivas, ni jerarquizadas, individualistas y centralistas, sino horizontales, múltiples y comunitarias.

Por otro lado, el proceso de reflexión de este trabajo se inscribe en un desarrollo acumulativo de varios años de intervención comunitaria con niños(as), adolescentes, jóvenes y organizaciones sociales que en distintos sectores de la zona sur de Santiago hemos estado involucrados durante la década de los años 90 . Es sobre esta base experiencial desde donde emanan estas reflexiones, que interpretamos a la luz de las formaciones socioculturales e históricas de la época que nos corresponde vivir.

En tal perspectiva, los «autores» de estas páginas, tan sólo son un instrumento que malamente pueden dar cuenta — sintéticamentede estos procesos, sin embargo, Mónica Bonnefoy L., Oscar González y Antonio Favreau M., son responsables de los dichos vertidos con afanes interpretativos, que buscan sondear los laberintos de las soledades en que se anidan los sueños de importantes sectores juveniles de nuestra sociedad. Finalmente, esperamos con estas líneas contribuir a un debate que recién se inicia y abre al conjunto de la sociedad, en donde se visualizan las profundas y graves fisuras que ella presenta en el respeto de los derechos sociales de los jóvenes.

\section{INTRODUCCIÓN}

Este documento no constituye un trabajo conclusivo o con pretensiones academicistas, sino más bien es el resultado de una larga experiencia y reflexión sobre los fenómenos que afectan a la sociedad chilena y especialmente al segmento juvenil. Pretendemos una caracterización que no parte de los marcos rígidos y estandarizados en los cuales se suele encasillar a este sector, es decir, partimos de una conceptualización abierta y amplia de lo que son los y las jóvenes. En tal sentido preferimos hablar — como viene siendo usual— de juventudes y no de juventud, dado que nos parece que lo juvenil es tan diverso, plural y complejo como la sociedad misma, en cuanto categoría de edad, sexo, social, étnica y en definitiva de referencias que aluden a la transitoriedad como etapa de la vida, y que por el contrario, la consideramos producto y productor de cultura. Por otro lado, queremos hablar desde nuestra propia experiencia y voz. En tal sentido las categorizaciones y análisis no se encuentran determinadas sola y exclusi- 
vamente por la discusión académica o la experticia investigativa de las ciencias sociales, sino más bien buscamos desarrollar una práctica dialogante con el sujeto que vivencia estos procesos y definiciones, donde el lenguaje adquiere la forma y el sonido de quienes lo profieren. Es decir, hablaremos desde unas concepciones culturales, filosóficas y políticas adquiridas en conjunto a una experiencia social en la que estamos insertos y desde donde nos explicamos las cosas, las manifestaciones del ser y el mundo.

Ante lo expuesto, queremos precisar que esta reflexión surge a propósito de la experiencia y trabajo que la Corporación Caleta Sur ha desarrollado en el transcurso de los últimos años y que esperamos contribuya como un aporte al debate y la discusión al interior de la dinámica social juvenil de este espacio.

Como escenario general, este documento intenta compartir una interpretación de las condiciones principales en que se encuentra, a nuestro juicio, la cultura occidental y particularmente la de Chile, con el fin de generar un marco comprensivo amplio en torno del fenómeno de las juventudes y cómo éstas se insertan en la continuidad histórica y cultural de nuestra época. Es decir, intentamos señalar una cierta cartografía, un mapa y un territorio, capaces de dar cuenta de las constantes de los y las jóvenes en el contexto de la modernidad.

La tan anunciada crisis cultural, de ya larga data, parece llegar a su fin, es decir, identificamos y podemos encontrar claros signos de una intersección que se manifiesta en las implicancias sobre la vida humana que ejercen las ciencias, la tecnología, y en general el conocimiento desarrollado en el marco de las profundas transformaciones del siglo XX y de las producidas en las últimas décadas en Chile.

Los soportes filo-ideológicos en los que se sostuvo el andamiaje de la modernidad y de la cultura greco-latina y cristiana durante estos dos mil años, se corresponden con un conjunto de principios éticos y axiológicos que se han desvitalizado en las dinámicas sociales de las comunidades occidentales, la carencia de un testimonio consistente y coherente desde donde se sostenga dicho andamiaje, que otorgue densidad e intensidad a dichas dinámicas que las ha terminado sepultando.

La desintegración a que se encuentra sometida la humanidad, la podemos identificar en el quiebre mente-cuerpo, pobreza-riqueza, vida-biologisismo, etc., factores que van constituyendo el espejo resquebrajado sobre el cual buscamos descubrir una identidad extraviada y fragmentada. La desintegración se experimenta desde la unidad de la experiencia vital. 
Los elementos de una separatividad manifiesta los podemos encontrar, particularmente, en el desarrollo de la modernidad. Puede dar cuenta de ello, la Declaración Universal de los Derechos Humanos que nos demuestra la profunda crisis de nuestra sociedad respecto de hacer necesaria la explicitación de una noción tan básica como el reconocimiento y respeto de un otro que no sea el sí mismo. Del mismo modo, la Globalización centrada en el mercado nos interpela respecto del tipo de sociedad que estamos construyendo y que desde los centros de poder se refuerza, desconociendo una mirada de Integralidad en las capacidades y necesidades de la persona humana, así como la aparición de un Estado, en el contexto del Neoliberalismo - centrado en la feroz acumulación-, que no asegura ni da garantías de un estado de cosas mínimo donde las personas puedan desarrollar su vida.

En este escenario está inscrita la situación que le corresponde vivir a un segmento de la sociedad definida como juventud. El encuadre sociocultural y político de este sector social, se define especialmente por la fuerza que se ejerce sobre ellos respecto al reconocimiento y a la dignidad de los y las jóvenes, de acuerdo a las condiciones existenciales y de vida que les toca vivir. Por esto la diversidad juvenil se encuentra sometida a categorizaciones, clasificaciones, estandarizaciones y un conjunto de nomenclaturas que se construyen desde una percepción externa y, por lo general, ajena a los intereses, necesidades y capacidades que ellos poseen. La conjunción de factores políticos, sociales, económicos, educacionales y laborales configuran panoramas estructuralmente diversos en la juventud y generan una multiplicidad de caracterizaciones sobre este sector de la sociedad que no se reconocen y no dan cuenta de ella.

La resolución de conflictos en la sociedad occidental se ha expresado tradicionalmente por medio de la confrontación. De esta manera, las resoluciones han sido en general coercitivas o evasivas y muy pocas veces han logrado ser asertivas e integradoras; de la misma manera en la relación adulto-joven. En efecto, en la actualidad en Chile podemos comprobar que la juventud es objeto de una política sistemática de control y represión social, expresada particularmente en cuerpos normativos y en políticas sostenidos desde el enfoque de seguridad ciudadana. Todas estas iniciativas e instrumentos, emanados desde una matriz adultocéntrica, se plantean con desconfianza frente a la juventud. Paradójica sociedad ésta que, por un lado, profesa el liberalismo como expresión única de la libertad y termina confrontada contradictoriamente con sus propias categorizaciones. 


\section{CONTEXTO: LOS MAPAS Y TERRITORIOS DE LA CRISIS}

Para reseñar la actual situación de crisis cultural, nos parece necesario recurrir a una cierta decursividad histórica, hacer una especie de racconto histórico-cultural que nos permita un acercamiento y una comprensión más acabada de aquello que hemos denominado crisis; entendiendo por crisis básicamente el momento actual de radical fugacidad y dispersión de los códigos axiológicos y de los vínculos más esenciales entre las personas. Al mismo tiempo, partimos de la base que los procesos culturales y epocales por los cuales nuestra modernidad occidental ha transitado no pueden ser expuestos en términos lineales; por tanto, esta mirada es también un intento arbitrario por señalar un escenario que es mucho más complejo que la suma de acontecimientos que aquí comenzamos a enunciar.

Tratando de establecer una especie de línea de tiempo en cuya continuidad histórica podamos dilucidar las claves del pasado, podemos encontrar los orígenes de la crisis en la cultura greco-romana y cristiana que configuran los valores y estilos de vida que finalmente la sociedad occidental ha asumido y que se desarrollan fuertemente hasta la alta Edad Media. Es así que desde el Renacimiento comienzan a esbozarse reacciones a aquella noción dominante, fundamentalmente, con el surgimiento de la burguesía (producto de la conformación de las colonias burguesas a partir del siglo XII, inicio de las primeras cruzadas); desde donde se construye un nuevo escenario: una noción dualística y una concepción teológica de la vida y la muerte, un orden centrado en la ley humana, un principio de autoridad basado en el poder coercitivo emanado de la «soberanía popular» y por la acumulación, la explotación de la naturaleza como fuente inagotable de riqueza; es decir, se transita de un orden recibido por Dios (teocéntrico) a otro producido por el ser humano (humanismo antropocéntrico).

Producto de todo aquello, comienzan a surgir los procesos del humanismo que buscan situar al ser humano al centro de todas las cosas. El nacimiento de la perspectiva - como percepción de la realidad - y la confianza en el progreso basada en la ciencia y la técnica, materializada y objetivada en el progreso, constituyen procesos marcados por la pérdida de la confianza en el advenimiento del reino de Dios en la tierra, marcado por una relativa tranquilidad luego de siglos de guerras y por la creciente comercialización entre las ciudades.

Se configura un cuadro que se inaugura con los deseos de humanización, de individuación y naturalización para terminar, pro- 
ducto de las promesas no cumplidas de la modernidad, en la deshumanización, masificación y la cosificación del ser humano y de la vida.

Aparece, entonces, la Revolución Francesa como un fenómeno de consolidación de las dinámicas culturales que se venían produciendo que representa, por otra parte, un giro sustancial, en tanto se consolidan las ideas fuerza de progreso y bienestar, que van a generar un camino de desacralización y la asunción, finalmente, de una determinada forma de racionalidad (paradigma positivista de corte cartesiano-newtoniano) como única forma de aproximación a la realidad.

Este fue el principio de una nueva era donde los intereses de las personas comenzaron a estar centrados en la búsqueda frenética por la felicidad, prometida por los ideales de la revolución y del progreso humanos; al lugar que antes ocupaba el paraíso (alcanzar el reino de los cielos) se sitúa la utopía (revolución social y sociedad perfecta) alcanzable sólo por el esfuerzo humano. Las teorías pasan a constituirse en las ideas del cambio y las revoluciones sociales irrumpen en el mundo con la fuerza de una realidad en la que aparece una nueva categoría, la clase social. Se configura así el escenario que daría paso a la llegada de la libertad; una libertad entendida fundamentalmente como negación del otro, una libertad que comienza donde termina la del otro, la libertad, finalmente, mercantilizada de nuestros días, una libertad centrada en el sujeto en cuanto individuo.

Por tanto, nos parece que los principales factores de ese agotamiento cultural en la sociedad occidental, los encontramos esencialmente - en la desacralización y secularización de la naturaleza y de la vida, resultado del proceso estructurador de la burguesía como clase rectora y conductora de la sociedad (que impone una manera de ser y estar en el mundo) a la vez que el proletariado como clase social al no lograr incorporar elementos catalizadores que la perspectiven como segmento conductor de la sociedad en su conjunto, en el marco de una revolución social, donde se conquisten las aspiraciones - ilustradasde libertad, igualdad y fraternidad, termina subsumida en las contradicciones de la dinámica burguesa en cuanto aspiraciones socioculturales.

De esta manera, el proletariado no tuvo la capacidad, a diferencia de la burguesía, de perspectivarse como sociedad en su conjunto, sino más bien se vio a sí mismo, a lo sumo, como una parte de ella, por tanto, fue incapaz de abandonar la condición de marginalidad que históricamente asumió. Quedando, finalmente, con la imposibilidad de generar un discurso propio y de constituirse en una alternativa integradora. 
Si la modernidad fue el momento explosivo (la orgía) de todas las representaciones, todas las ideas, todos los fines y todas las utopías colectivas; el actual momento representa la radicalidad del valor (en tanto categoría axiológica) en su fugacidad, en tanto la imposibilidad de unos criterios ordenadores universales junto con la asunción de lo político y lo económico como el éxtasis explicativo del momento actual; es, en tanto, la dispersión, la radical fragmentación, social y existencial (colectiva e individual) de los seres humanos en la búsqueda de sentidos. ${ }^{1}$

Se instala, finalmente, un escenario que deja al ser humano en una situación de orfandad y fragilidad difícil de sobrellevar. Es precisamente en el contexto de esa época en que ya comienzan a desfallecer las promesas de la modernidad, (fin del siglo XIX, principios del siglo XX), cuando se aproxima cada vez con más fuerza la oscura noche de los tiempos. Es entonces cuando comienza a hacer su aparición la juventud, que se transformará en la etapa difícil y complicada para los tiempos de crisis. Es así que la sensación de no futuro, de abulia y apatía se hace sentir fuertemente en una buena parte de las juventudes de nuestros días.

Si bien se podría hablar de Juventud más propiamente a partir de la mitad del siglo XX, no es menos cierto que, en el contexto de nuestro país, se señala que variados procesos estarían marcados por una fuerte presencia de jóvenes. En tal sentido el historiador Gabriel Salazar afirma que son los jóvenes los que han producido los cambios en nuestra historia. Ciertamente se reconoce una incipiente aparición de los jóvenes en aquella juventud antisistémica de principios del siglo $\mathrm{Xx}$, la que fue protagonista de uno de los primeros intentos de reforma educacional que se conocen así como de las primeras, aunque incipientes, protestas contra el servicio militar. De cualquier manera, entendemos la juventud como una etapa que si bien está en un permanente proceso de construcción, es aquélla que siendo tal logró articular un discurso generacional propio, es decir, un habla que diera cuenta del sentir y el pulso de una generación; aquella juventud que construyó un sentido político, social y cultural, de aquélla que elaboró un lenguaje, una postura y una visión propia del acontecer del mundo y de la sociedad; de aquella juventud, en definitiva, que se constituyó en el sonido crítico y disonante frente a los valores de la sociedad burguesa.

1 Carlos Badilla y Oscar González: «Apuntes sobre la globalización». Documento de Trabajo Interno. Santiago, Corporación Programa Caleta Sur, marzo de 1998. 
Tal como la sociedad ha estado sometida al largo periplo que hemos intentado graficar, la juventud ha sido el segmento privilegiado de los avatares y acontecimientos de un tiempo que con sus bruscas transformaciones ha extraviado la brújula y ha resquebrajado cada vez más los sueños y las esperanzas de la humanidad. De ahí que la juventud se haya convertido en el chivo expiatorio predilecto de una sociedad que no da cuenta ni entiende los fundamentos más elementales del agotamiento y el cansancio que expresa el actual momento cultural.

\section{GLOBALIZACIÓN: \\ LOS DERROTEROS DE LA DESINTEGRACIÓN}

El problema de la globalización es que los globos se revientan.

Los cambios geopolíticos acontecidos durante las últimas dos décadas han generado profundas transformaciones en el concierto mundial, el término de la guerra fría, la caída del muro de Berlín, la asunción del eje Norte-Sur y del Asía-Pacífico, la revolución en la informática y las comunicaciones, los modos de producción y servicios, la emergencia de nuevos actores sociales, la crisis de soberanía y de la autoridad coercitiva, centralizada, jerárquica e individual; la de la democracia representativa, la de clases y del Estado-Nación, de las utopías y de los sistemas de representación tradicionales, son los factores que nos ponen en el escenario de la globalización.

En efecto, la virtualidad, la simultaneidad o la instantaneidad en las relaciones e intercambios (componentes esenciales del proceso globalizador), ponen de manifiesto la necesidad de significar las características de las comunicaciones y de los vínculos humanos, desde donde se puedan connotar los fundamentos de los giros culturales que se comienzan a vivenciar.

En el proceso de la globalización, el mundo se ha ido constituyendo en bloques económicos, primero, y luego ha avanzado hacia bloques políticos muy a la usanza de la guerra fría. Estos bloques son liderados por las mismas potencias que han gobernado los procesos anteriores en cada una de las regiones. Es así que el bloque AsiaPacífico está guiado por Japón y los llamados tigres del Asia; por otra parte, el bloque de la comunidad económica europea, encabezado por Alemania, Inglaterra y en menor medida Francia, y por último, el bloque de América con EE.UU. liderando, y con la pretensión aún, de 
conseguir una zona continental de libre comercio. La configuración de estos bloques de características económicas y geopolíticas, pareciera sostenerse en concepciones etnocéntricas y totalizadoras, autoritarias y coercitivas, que desdicen los presupuestos liberales en que señalan haberse fundado en las postrimerías del Renacimiento.

De tal manera que el poder coercitivo que históricamente recaía en las élites dominantes de cada país se ha transnacionalizado, esto pone de relieve una situación en la cual se comienzan a generar las tensiones planteadas por la globalización económica que tienen su efecto en lo cultural, esto es, la tensión entre la anunciada integración versus identidad, soberanía e independencia.

La globalización se entiende como la existencia de un solo gran mercado global, lo que significa que en el ámbito de los distintos mercados de bienes, servicios y de capitales ya no están relacionados por vínculos esporádicos, sino que hoy se encuentran estrechamente ligados, de modo que los precios se determinan en los mercados mundiales, las inversiones observan las oportunidades en todos los países antes de tomar las decisiones, la propiedad de las empresas ya no necesariamente se asocia a los empresarios nacionales de un país.

La globalización es un proceso centrado fundamentalmente en torno a los cambios de ejes geopolíticos de dominación territorial, en cuyas bases se encuentran los procesos de producción y comercialización. En este marco, la economía de libre mercado ha reposicionado el rol y validez del mercado como fuente y mecanismo de los procesos de desarrollo social y económico de las sociedades. Así también, el papel social que de éste se proyecta: subsidiariedad, jibarización del Estado, libre Iniciativa, etc., configuran la readecuación del poder coercitivo a nivel internacional en haras de la acumulación y concentración hegemónica del poder.

Finalmente, la lógica de la globalización apunta, contradictoriamente, en dos direcciones; de un lado, la corriente a favor de liberalizar el comercio internacional y que procura derribar todo aquello que impida el libre tráfico de productos y capitales y hasta ciertos límites de tecnología y conocimiento y a debilitar las soberanías nacionales y la identidad. Por otro lado, los Estados nacionales se asocian en bloques económicos o zonas de libre comercio entre sí, para establecer barreras proteccionistas contra otros bloques en defensa de sus intereses. La disyuntiva en la concepción bi-polar es autonomía o dependencia.

a) Identidad e identidades 
Paralelamente a la globalización se inician procesos de descubrimientos en lo territorial (lo local), aquello que se origina en la dinámica de lo cotidiano e inmediato, es decir, se vuelve la mirada al terruño, a lo que pasa aquí y ahora. Este pendular humano, tan humano, parece ser un ejercicio en la historia de la humanidad. Así, desde lo universal a lo particular, desde lo general a lo específico, desde el mapa al territorio. El reconocimiento de lo específico, de lo local, del territorio, nos impulsa a considerar que lo propiamente humano se constituye desde planos insospechados, donde la inmediatez de las relaciones cara a cara, la apropiación e identidad con el territorio local, van configurando procesos de identidad cultural propios y específicos en la posesión de fragmentos de la ciudad. Identidad y sentido, pertenencia y comunidad, van configurando un escenario que resignifica las relaciones de poder, humanas y de satisfacción de necesidades.

Desde esta mirada, los análisis se trasladan al terreno de la cultura, y desde ésta, nos es necesario entender la identidad como una construcción que fundamentalmente se va haciendo, se va construyendo, es necesario, por tanto, establecer un puente entre una noción deconstructiva de la identidad, para entenderla como identidades, y las posibilidades de encontrar aquella señal que nos permita descubrir en la integración anunciada no la homogeneización y uniformización de los gustos y la vida de las personas, sino aquella imagen mínima donde se conjugan miles de rostros diversos y miles de apuestas distintas.

Es desde esta mirada que entendemos que la identidad no puede ser concebida en términos esencialistas. Es decir, la afirmación purista que nuestra identidad se encuentra única y exclusivamente en las raíces aborígenes constituye una visión simplista y poco integradora, así también, como afirmar que nuestra identidad es sólo esa imagen de postal que se ha vendido, donde aparece una Latinoamérica pulcra, blanca y ordenada.

Nos parece que los lugares de la identidad latinoamericana están más en aquellas descripciones donde lo mestizo, la hibridación y el sincretismo aparecen como las referencias; la postulación de que la identidad es un evento dinámico que fundamentalmente se hace en lo cotidiano, refundándose en conjunto con los fenómenos culturales y humanos que no dejan de surcar el mundo en el cual habitamos, y donde el acto mismo de habitar constituye una suerte de ir y venir, en y desde la cultura, de ese habitar que es también un mirarse.

Mirarse, en el caso de Latinoamérica, es una suerte de consti- 
tución desde una relación melodramática con el medio, inserta en una cultura donde el dolor ocupa un lugar preponderante. De ahí la búsqueda de la felicidad, el incansable periplo hacia la satisfacción y el placer, aun cuando hoy día sea la felicidad prometida a plazo por los créditos para el consumo fácil.

«La experiencia común se gesta, transcurre, se modifica como proceso, en la continuidad de los hechos de todos los días», ${ }^{2}$ en el ir y venir callejero del tránsito cotidiano se configura la identidad cultural de los pueblos, con el acto del recogimiento y de la reflexión cotidiana se vuelve a la calle, a lo público — el espacio de todos y de nadie- , al ejercicio dialogante. El domicilio, el refugio, el espacio protegido para la recuperación de las fuerzas del desgaste público, para la evaluación del acto de vivir, para recuperar esa certeza vital con la que cada día me levanto, seguro de ser el mismo que anoche se acostó.

Precisamente, en esa vuelta a la calle aparecen y afloran las distintas identidades que pueblan lo juvenil, aquellas identidades donde lo propio no es más que una conjugación de aquello que denominamos lo nuestro con lo que percibimos como lo externo. Las paradojas de la globalización han propiciado precisamente esa aparición, la de una variedad de apuestas y expresiones, las cuales se han constituido mayoritariamente en modas, pero también en tendencias y movimientos.

En la mixtura neoliberal y posmoderna de nuestros días se reflejan claramente los cruces de forma y fondo; de identidades que constituyen modas y de identidades que constituyen tendencias y posteriormente movimientos. Así como son los pueblos los que otorgan identidad a los países, los y las jóvenes son el (los) grupo(s) que construye(n), mayoritariamente, esas identidades: diversidad, eclecticismo de las modas e hibridación con la cual están constituidas; las tendencias marcan definitivamente el ingreso a la órbita cultural del mundo globalizado de parte de esas juventudes fascinadas con los adelantos tecnológicos y muchas veces narcotizadas de imágenes mediáticas.

\section{LOS POSIBLES ESCENARIOS JUVENILES}

2 Humberto Giannini: La experiencia moral. Santiago, Editorial Universitaria, 1992. 


\begin{abstract}
Sospechoso, sometido a duda, aislado, olvidado quizás, dudando de su propia identidad, escéptico a veces y, sin embargo, apuras cielos pretende... cruzar tierras, apurar cielos...
\end{abstract}

El análisis, las taxonomías, las clasificaciones y toda la tecnocracia social que ha operado en el transcurso de esta década sobre el sector juvenil, ha estado dirigida por una institucionalidad que se alejó definitivamente de las características y condiciones propias de las juventudes del Chile de hoy. Efecto de ello son los fracasos de las políticas públicas hacia este sector que no han sido intérpretes ni tampoco comprensivas, no sólo con las necesidades y carencias de los sectores juveniles sino, lo que es peor, con sus potencialidades y capacidad de propuesta.

En este sentido, la retracción del Estado producido por la globalización, que famélico facilita el anquilosamiento de concepciones y estrategias políticas inadecuadas, sin atención a las características de las juventudes de los 90. Por ello, consideramos necesario establecer mecanismos de participación que integren la experiencia de los y las jóvenes de acuerdo a las particulares condiciones y escenarios que a éstos les corresponde vivir. Cuando abordamos, en los prolegómenos de este texto, una perspectiva cultural estamos aludiendo a la potencial crisis de una matriz que se ha establecido desde categorías generacionales, de clase y/o género en cuanto a la segmentación y quiebre de las identidades que ello significa y que impactan al conjunto de la sociedad en la definición de las políticas públicas y que se refuerzan con la no incorporación de la diversidad emergente de actores sociales, generando de hecho exclusión y marginalización social.

La mirada adultista en torno a los fenómenos juveniles ha devenido en que esta etapa sea identificada solamente como un proceso de transitoriedad hacia la madurez y hacia una adultez responsable, identificando el período juvenil como un largo ritual de paso entre una infancia que se prolonga en romanticismos y sueños hasta la realidad fáctica de una adultez preñada de obligaciones y responsabilidades sociales. Si bien, la transitoriedad es reconocida desde los discursos oficiales como un hecho concreto, se articulan discursos acerca de ésta que redundan siempre en la mirada del joven en tanto potencial adulto. Junto con lo anterior, persiste la mirada de la carencia y/o daño, por sobre el de la potencialidad, es decir, la posibilidad de la vivencialidad del aquí y el ahora es aceptada fundamentalmente dentro de la mirada de problema. Los discursos adultos insisten en situar la etapa llamada juventud como una situación problema, como una etapa a superar, 
como un paso necesario para ganar experiencia para ser un sujeto útil a la sociedad en tanto adulto.

Se produce, por tanto, el conflicto con el llamado mundo adulto, primero en relación a la construcción de mundo que se hace desde los y las jóvenes, ya que esto pareciera estar marcado por cuestiones que lo particularizan. En tal sentido, el quiebre con el mundo adulto se produce en el momento en que lo juvenil se constituye y se autopercibe como una realidad concreta y definida con un mundo e ideales propios, las construcciones son distintas y las fisuras se producen cuando los discursos adultos intentan cargar de una cierta moralidad los actos y las actitudes de los jóvenes, planteándose el conocido divorcio entre lo privado y lo público. Aquellas juventudes de hoy, disgregadas, con una actitud antipática (y no apática) con el sistema formal de participación, son las que buscan abrirse espacio en una sociedad que sólo los valora en tanto sujetos del ilusorio consumo y en tanto potenciales votantes.

Las juventudes son las que han articulado variadas hablas, donde confluyen los decires de los jóvenes. Pero el hablar, el decir, es hoy en Chile un ejercicio escaso, pero además un ejercicio peligroso dependiendo de quien sea la voz que habla, cuando la voz que habla es la voz de los jóvenes; ocurre entonces que ese habla individual o colectiva se confronta con el habla y el discurso bien intencionado del mundo adulto, por eso el decir algo se constituye en una necesidad, en una vital posibilidad de articular la voz, que diga las cosas que la razón siente y los sentidos interpretan.

La juventud tradicionalmente ha sido considerada como un momento etáreo en la vida de los sujetos en donde las características se determinan por factores bio-sico-sociales, que establecen el tránsito entre la infancia y la adultez. Las condiciones de transitoriedad de esta etapa, tienen como finalidad llegar a la adultez integrada socialmente y en ella desarrollar una estructura de la personalidad en la cual la sociedad fija ciertas posiciones y asigna ciertos roles diferenciales los que van constituyendo cultural y socialmente a los sujetos. Esta conformación se desarrolla dentro de un proceso de moratoria en el que el joven permanece viviendo, como en un tiempo de espera, hacia la supuesta consolidación dada por la «madurez», condición en la que se supone ha aprendido funciones, roles y oficios para el reciclaje del sistema social. ${ }^{3}$

Sin embargo, para citar sólo un ejemplo, la situación de asu- 
mir un rol «activo y maduro» por las juventudes en la sociedad, se contradice en cuanto este sector se ve afectado directamente por los altos índices de cesantía, lo que le impide justamente asumir lo que la sociedad reclama de ellos.

En el proceso de constitución de la personalidad juvenil podemos encontrar las primeras tensiones que se generan en la estructura de dicha personalidad, especialmente para los jóvenes urbanopopulares, quienes se enfrentan al proceso de moratoria con tiempos y ritmos distintos a los tradicionalmente establecidos y que terminan finalmente frustrando los propósitos de integración social adulta.

En la introducción de este texto hablábamos de juventudes y no de juventud, dado que «la idea de un sujeto juvenil único es, por lo bajo, una pretensión autoritaria» ${ }^{4}$. Es decir, la diferencia no está dada solamente por un juego de autoproducción estética o de cosmetología postmoderna. La diferencia, también, pareciera estar dada por definiciones éticas, en torno a las cuales la diferencia suele aparecer como negación o incluso como contradicción, en tanto los referentes juveniles parecieran provenir siempre desde la influencia de las modas, las tendencias y las ofertas del mercado. El paradigma cultural actual nos menciona a una juventud seducida por el valor artístico de la performance; pero y en definitiva, ¿las juventudes chilenas constituyen una promesa o una amenaza para el Chile del presente y del futuro?

\section{a) Juventudes, participación y control social}

Las últimas cumbres de presidentes realizadas en la región han tenido como temas destacados en sus agendas de discusión la gobernabilidad, la seguridad regional y las fronteras internas. Éstos que aparecen como los temas centrales de las discusiones, han estado reforzados por la idea fuerza de que la forma de mantener a la población tranquila y acatando los costos del modelo, son en parte, los planes y programas de participación social.

En tal sentido cabe afirmar que la participación es siempre un producto de determinados ejes ideológicos en juego (tanto de la cultura hegemónica como de los paradigmas básicos del último siglo), tal como lo fue, por ejemplo, durante la «promoción popular» (en el gobierno de Frei Montalva) en el contexto de la «Alianza para el Progre-

$4 \quad$ Alejandro Reinoso: «Jóvenes de los 90: datos de un mosaico en busca de un sujeto social». Primer informe nacional de juventud. Santiago, INJ, 1994. 
SO».

La participación como mecanismo social es cada vez más un elemento de control social, es decir, la participación entendida fundamentalmente como la integración social a determinadas propuestas que ofrecen los canales regulares para la expresión ciudadana. En tal sentido el Estado (desde los programas de participación) ha actuado como un catalizador de las esperanzas y sueños de la gente a la vez que como elemento coercitivo frente a las demandas más radicales de expresión.

Frente a esto, cabe afirmar que la participación ha sido una de las más brillantes articuladoras de la pax social. Queremos entender participación como la virtual injerencia de la gente no sólo en lo social y lo político, que es como se la ha entendido tradicionalmente, sino también en la posibilidad de alcanzar los bienes de consumo, dado que «mientras no se asuma que las prácticas de consumo son, vitalmente, modos de hacerse parte de la sociedad [...] no será posible abordar adecuadamente los nuevos fenómenos de la participación social» ${ }^{5}$, así como estar en las decisiones municipales de tipo formal y, en general, en todo tipo de consultas que legitimen la llamada opinión publica.

Se adopta, por tanto, un discurso donde se asume la dictadura de las mayorías como único referente válido para tomar las decisiones, bajo la premisa de que lo que piensan las mayorías es lo mejor para el país.

La participación en los canales formales asegura, también, la carta de ciudadanía: soy ciudadano en la medida que expreso mi voz en las instancias formales de participación y en la medida que participo, con mi poder adquisitivo, de las bondades del mercado. La participación queda reducida así a una raya en un papel, en el caso de la participación política, a una marca en el rating semanal de la televisión.

Por tanto, es la propia sociedad —en un sentido ético- que permite la articulación con el mercado haciéndose parte de las políticas tradicionales, donde la participación es entendida como la expresión políticamente correcta de un grupo de personas que asisten a una terapia social de consumo simbólico. En ningún caso la participación es entendida como el protagonismo con el que siempre ha sido anun-

5 José Joaquín Brunner: «Participación y democracia: nuevos y viejos dilemas». Temas de Participación. Santiago, Secretaría General de Gobierno, 1996. 
ciada y vendida.

Se instala finalmente un peligroso círculo vicioso donde el poder escucha a la gente, como un acto de suma democracia y, por tanto, se implementan las políticas que la gente quiere... Desaparición total de lo político y del protagonismo social bajo la hegemonía de la participación ciudadana, pura estandarización de los anhelos de cambio de una sociedad civil fragmentada y atrapada en la fascinante fugacidad comunicacional de la posmodernidad chilensis.

Por ello, consideramos que la participación es un concepto que alude y contiene a más partes integrantes, interdependientes y activas, como un sistema que se orienta hacia un sentido predefinido como matriz cultural, que se expresa en una relación dinámica e interdependiente de los elementos y factores que la constituyen.

Los conflictos entre las partes desarrollan y generan tendencias y sentidos que se constituyen, unas a otras, en factores hegemónicos para dar u otorgar fuerza y clara orientación a los fenómenos que se vivencian. Las partes son los eslabones de una cadena que representan identidades y sentidos específicos y sensibilidades afines.

Las dinámicas que se producen entre las partes reflejan el fenómeno, en su calidad y características, de las condiciones de la participación. Este fenómeno y ejercicio lo podemos encontrar en distintos niveles y ámbitos: la naturaleza, la vida orgánica, la existencia humana. Ellos contienen características de mucha similitud sobre las cuales, comparativamente, podemos aprender.

La interacción entre lo común y lo distinto es la fuerza necesaria que permite el pendular del movimiento de la participación. Es este movimiento el que da vida a la participación juvenil en todas sus posibilidades y complejidades.

El potenciamiento de lo distinto, que es en lo cual se conjugan las obsesiones y los deseos de lo juvenil, crea posibilidades que pueden generar una participación incluyente o excluyente. Si ocurre el fenómeno de una participación excluyente se produce, entonces, una fisura en la cadena comunicacional, se inicia un lento proceso de rompimiento con la matriz cultural hegemónica, lo cual puede traducirse a la larga en una contracultura que desate un proceso de recambio de la matriz cultural dominante. La participación juvenil se ha debatido históricamente entre la necesidad de generar una contracultura y la necesidad de integrarla para transformarla, finalmente, en cultura.

Desde estas concepciones, podemos aseverar que el tránsito 
de la participación ha sido entre la conservación, la articulación del orden establecido y la idea del cambio social, la discontinuidad entre articulación y rompimiento, reforma y revolución, continuidad y ruptura. En los linderos de lo juvenil, la participación ha representado esa disyuntiva entre ser parte o estar fuera.

Como se mencionaba anteriormente, la participación parte siempre de un sustrato ideológico; así se han articulado miradas en torno a la participación juvenil asociadas a la anomia y más recientemente a la apatía, «la lejanía de los jóvenes respecto de la actividad política les ha ganado el apodo de apáticos, lo que refleja una percepción limitada de su participación pues no reconoce su amplio accionar». ${ }^{6}$ Por tanto, la participación aparece para la gobernabilidad como la tabla de salvación, «conclusiones preliminares de diversos estudios apuntan a que en los sectores marginalizados todo avance en el campo de lo organizativo reduce la amenaza de comportamiento anómico y rebelde, particularmente grave en los jóvenes», ${ }^{7}$ mirada predominante y hegemónica acerca de los fenómenos juveniles a los cuales se les percibe como una constante posibilidad de amenaza si éstos no están controlados por programas formales de participación.

Los discursos y las miradas oficiales e institucionales que se fueron articulando en los noventa acerca de lo juvenil dan cuenta de la percepción de esa juventud como una juventud amenazante, no participativa de los canales autorizados de participación.

Los espacios de la participación se han ido trasladando desde décadas anteriores hasta ahora, en el caso de los jóvenes, desde las maneras formales de organizarse hasta las nuevas formas de hoy donde, por ejemplo, la militancia en juventudes políticas se ha trasladado hacia otro tipo de organizaciones de carácter menos formal y sobre todo menos jerárquicas, formas más horizontales (figura de colectivos juveniles, por ejemplo). Esta noción de participación podría comprenderse como la necesidad de recrear formas de asociatividad basados no en entramados y rígidos planes y programas, sino en el hecho real de que participar es siempre hacer algo que tiene que ver conmigo y que va en directa relación con lo que soy y lo que puedo llegar a ser.

b) Participación, inscripción electoral y protagonismo político

$6 \quad$ InJUV: Los jóvenes de los 90: el rostro de los nuevos ciudadanos. Segunda encuesta nacional de juventud. Santiago, InJuv, 1998.

7 MidePLAN: «Participación de la comunidad en el desarrollo social; logros y proyecciones». Santiago, MidEPLAN, 1992. 
En los ejes de participación está fuertemente instalado el tema de la inscripción electoral como una de las señales de participación de los y las jóvenes y desde la cual se ha esbozado, por ejemplo, el término de apatía. En tal sentido, las elecciones generan hoy, a más de una década del plebiscito de 1988, una imagen muy distinta a la que se tenía en ese entonces; es una imagen que ha ido progresivamente desdibujándose,

En 1988, de cara al plebiscito, dos millones 676 mil 185 electores entre los 18 y los 29 años acudieron a los registros electorales, lo que representó el $35,9 \%$ del total de inscritos, que en ese entonces alcanzó a siete millones 435 mil 913 personas... Este año los jóvenes sumaron sólo un millón 153 mil 310, es decir, equivalen al 16,4\% del universo electoral». ${ }^{8}$

Las cifras son elocuentes. Las razones de estos porcentajes pueden sin duda ser variadas, pero es indudable que la importancia que los jóvenes le asignan a la participación política en tanto lo electoral, no es la misma de hace unos años atrás. En este respecto las miradas y las opiniones son claras, «yo no me he inscrito porque considero que inscribirse es como hacerle el juego al sistema para que siga funcionando como está funcionando...». ${ }^{9}$ Igualmente en los sectores populares se cuestiona la inscripción electoral como una herramienta eficaz para contrarrestar problemas de fondo. «...Yo no me he inscrito porque para la gente no hay oportunidades... yo antes era joven y no me preocupaba mucho sí tenía o no tenía, ahora tengo dos hijos y las cosas cuestan, no llega ayuda para nada...» ${ }^{10}$. Es claro, por tanto, que ciertas percepciones que aquí se arrojan desde distintos mundos y realidades reflejan que el tema de la participación entendida como inscripción electoral genera fundamentalmente indiferencia o, por lo menos, no se aprecia como un tema fundamental a la hora de las preocupaciones más importantes de los jóvenes, dado que la sensación

8 María Angélica Pérez: «¡Atención, jóvenes! Inscripciones de ultima hora». Santiago, El Mercurio, 1 de agosto de 1999, cuerpo D.

9 Entrevista Marcela, 22 años, estudiante de Periodismo Universidad ARCIS, video «Juventudes», Santiago, Caleta Sur, 1999.

10 Entrevista Priscilla, 19 años, dueña de casa, dos hijos, población Santiago de Nueva Extremadura, sector El Castillo, comuna de La Pintana, video «Juventudes», Santiago, Caleta Sur, 1999. 
más sentida es la de decepción y desazón general de las posibilidades reales de participación que un espacio como el electoral.

Otro de los ámbitos centrales dentro del tema de la participación es el de la dimensión más política. La experiencia de lo político tiene en los jóvenes expresiones y sensaciones tan diversas como la juventud misma. Al respecto, el sistema formal ha elaborado ciertas miradas no necesariamente consecuentes o coincidentes con las miradas que los propios jóvenes tienen,

La cultura política de los jóvenes hereda la sensibilidad de un período en el cual los mecanismos de representación política estaban proscritos. Los jóvenes de los 80 , a pesar de su participación en las protestas democráticas, llegaron a inscribirse en los registros electorales luego de una campaña comunicacional centrada en sus propios intereses, más que a partir de su propio impulso. Las finalidades que los jóvenes asignan hoy a la política aparecen coherentes con la desvalorización de los sistemas de representación que vienen de la socialización política... ${ }^{11}$

Las miradas tanto desde el sentido común como desde las elaboraciones propias de los jóvenes, encuentran en la política y especialmente en sus representantes, los políticos, el blanco necesario hacia el cual dirigir los dardos de la frustración sentida frente al fracaso de las promesas eternamente dadas y nunca cumplidas por el mundo político. Por tanto, pareciera que la percepción no es totalmente gratuita o producto de la «socialización política de los jóvenes» como sugiere el INJUV; quizás las respuestas están más dadas desde aquel sentido común construido y masticado por los jóvenes en torno al mundo político, «la política, sinceramente es como un centro de madres, que se preocupan sólo de los que están en el centro, los de afuera, nada», 12 «encuentro a la política como muy utópica... hay un discurso que te lo dan montones de políticos pero a fin de cuentas de eso sólo tres cuartas partes es cierto, lo demás es una cuestión como individual, es como sacar un provecho y basarse en una propaganda y ya después no cumplirla, es como que te venden la pomá nomás...». ${ }^{13}$ Los imaginarios en relación al mundo político están presentes en variados sectores de esas juventudes, por tanto cabe argumentar que los

11 InJuv: «Segunda encuesta nacional de juventud. Cuadernillo Temático №3: La participación social y política de los jóvenes». Santiago, InJuv, 1997.

12 Entrevista Priscilla: loc. cit.

13 Entrevista Valeria, 21 años, estudiante de Trabajo Social, Universidad ARCIS, video «Juventudes», Santiago, Caleta Sur, 1999. 
jóvenes se encuentran en una actitud antipática con aquellas formas de hacer política desde los círculos hegemónicos.

Las diversas formas de organizarse están inscritas en una forma de apreciar la política hoy y la participación al interior de ella. Es en este sentido, que se inscriben experiencias más horizontales de participación, instancias no jerárquicas que buscan terminar o eliminar los vicios de esa forma tradicional de hacer la política, la que al decir de los jóvenes estaría enmarcada fundamentalmente en la imagen de los partidos políticos.

La participación política puede no ser una preocupación central para una mayoría de los jóvenes, empero ésta deviene en una participación cada vez más creciente en espacios que, tradicionalmente, no son percibidos como espacios políticos sino que como espacios culturales, artísticos o de índole comunitaria. Aun cuando estos espacios muchas veces tengan contenidos altamente politizados, como la reivindicación de las raíces culturales o la necesidad de lo artístico como canal de expresión social — por ejemplo—, éstos no son apreciados por los discursos oficiales como espacios de participación política.

Cabe agregar que los denominados espacios de participación, también, tienen que ver con las expectativas que determinados espacios generan o generaban entre los jóvenes. Es así que en el caso de los espacios educativos existía una fuerte connotación de superación y de promoción social; hasta hace una década, por lo menos, era importante estudiar como una cuestión que habría posibilidades de futuro sobre todo en los sectores populares; hoy día pareciera que la imagen se presenta de una forma distinta sobre todo en los estratos bajos. La educación ya no es percibida como un promotor de movilidad social lo que ha hecho aumentar notoriamente la deserción escolar en edad temprana, fundamentalmente, para buscar oportunidades laborales. Se desperfila, con ello, un espacio que era promotor y lugar de participación de los jóvenes.

Parecieran, por tanto, explicarse las reacciones y las resistencias de los jóvenes y que éstas se enmarcan en una mirada dura acerca del sistema político y en concreto del mundo político en su condición de mundo adulto, se produce finalmente una confrontación con ese mundo. Se generan reacciones que tienden a situar las expresiones de divergencia como situaciones de rebeldía o desadaptación; pareciera, sin embargo, que estas reacciones muestran fundamentalmente eso, reacciones desde un mundo que se comprende poco y se acepta menos...

c) Territorialidad, cotidianeidad y actoría social... 
La juventud urbano popular establece una relación de conflicto con el sistema político formal desde la simple condición de ser juventud clasificada y calificada como marginal.

La participación en los sectores populares está dada por las múltiples expresiones y diversidades de los y las jóvenes y que implica el compromiso de participar en la resolución de sus propias problemáticas. Siguiendo a Salazar,

Es imposible no participar en la producción histórica de sí mismo. En el mundo de la vida propia. Hasta el más marginal y excluido de los seres humanos es activo en la producción de tejido social, económico y cultural, en tanto conectado a su propia supervivencia. ${ }^{14}$

En tal sentido, pareciera que esta adscripción a la dinámica de la participación indicaría la inutilidad de los planes y programas formales articulados desde el poder central, en tanto la posibilidad de participación real está dada, al decir de Salazar, por un desafío y aprendizaje de participación, expresado fundamentalmente en los sectores más postergados y más excluidos, entre los cuales los jóvenes se encuentran como grupo destacado.

Formación primigenia de ciudadanía, como lo entiende Salazar, es una noción de participación que tiene más que ver con una cuestión que precede a la calidad de ciudadanía y que refiere a estructuras relacionales primarias, donde éstas se inscriben en un medioambiente o en un paisaje común, con sueños y frustraciones comunes. Esto produce un acercamiento difícil de apreciar en otras dinámicas sociales donde los niveles de competencia y exitismo están más fuertemente marcados.

Aquí la participación es entendida, fundamentalmente, como convivencialidad, como la capacidad de estar con el otro en tanto ese otro es como yo, siente y sufre las mismas cosas y tiene las mismas carencias que yo; así, la participación se vivencia como una cuestión de la cual soy cotidiano protagonista.

Por tanto, podríamos aseverar que la participación en los sectores urbano populares tiene un rostro tremendamente cotidiano, es una participación vinculante, cara a cara, una participación que se da no sólo en los espacios formales de reunión o planificación, sino tam-

14 Gabriel Salazar: «Editorial». Proposiciones N²8, Santiago, Ediciones SUR, 1998. 
bién en la informalidad del encuentro callejero, en la posibilidad de hacer otras cosas. Esta participación vinculante está relacionada con una territorialidad concreta, con un estar y con un lugar en el mundo que permite generar identidad, ser actor, ser protagonista, en lo que podríamos denominar como una especie de ciudadanía alternativa, fuera de los canales formales o de las obligatoriedades que el sistema impone. Es una ciudadanía que se genera por el hecho de participar en la posibilidad de la autogestión del propio destino.

Este lugar en el mundo está relacionado con la vinculación entre los pares, con la relación horizontal que se construye con aquéllos que viven en el mismo territorio, en relación a un sujeto individual y colectivo.

La participación como la entienden los jóvenes de los sectores populares los pone en tensión con el medio, con aquel medio que mira y aprecia desde la desconfianza y la vigilancia, desde la seguridad ciudadana. El ser joven en los sectores populares significa ponerse en tensión con el mercado por mejores posibilidades de trabajo, ponerse en tensión con el sistema educativo por mejores posibilidades educacionales y de capacitación, ponerse en tensión con el sistema formal de participación por espacios. Es ponerse, finalmente, en tensión con el sistema represivo que mira con desconfianza y recelo el deambular y el modo particular de generar participación de los jóvenes pobladores. Finalmente, una tensión determinada por las condiciones de exclusión social.

La participación que se expresa en los sectores juveniles poblacionales está muy relacionada con la solidaridad, precisamente con aquéllos que se quedan fuera de la resciliencia social. La participación juvenil a nivel popular arranca desde una situación y una cotidianeidad que la confronta a diario con las problemáticas sociales que están en el TOP de los ranking de las políticas sociales, por tanto el eje central de la participación en estos espacios sociales es la motivación constante a hacerse parte de las soluciones más que de los problemas, aquella motivación que invita a levantarse cada día y caminar por la población y mirarla y quererla, a pesar (o en realidad junto con ellas) de la drogadicción, la violencia, el vacío, el control, la vigilancia y el desamparo que inunda cada esquina de los barrios pobres de Santiago.

De modo que la participación ha sido una forma de sortear las barreras tanto culturales como comunicacionales que se imponen en los sectores poblacionales, ya que cuando nos referimos a esta juventud que participa, hablamos de una diversidad de juventudes y de ex- 
presiones. También, existe la realidad de ver a,

Cada persona encapsulada en el ghetto que la sociedad teje en torno a su lugar de origen, hablamos desde la imagen de un mundo de calles interminables, de niños buscando los afectos perdidos... De un mundo definido desde los parámetros de la pobreza, pero desconocido desde lo humano, que se gesta y convive entre las barreras de la marginalidad. ${ }^{15}$

La posibilidad de tener un lugar en el mundo responde a la necesidad de enmarcar la acción participativa en un contexto real y concreto, con una territorialidad, una cotidianeidad y sociabilidad comunes, en la posibilidad de generar protagonismo y finalmente actoría social, para transformarse en actores y actrices de una historia que se entrama y se teje en los límites de las cifras macroeconómicas, en los intersticios de la seguridad ciudadana, una historia que se teje y se enreda en la cotidiana necesidad de pertenecer y ser parte.

Una relación vinculante, que es el sustrato de toda participación entendida como protagonismo, es la posibilidad de sentirse afectado por el otro, es compartir un ethos y un pathos común. El vínculo aparece como la herramienta necesaria, como el componente enfrentado a la tecnocracia, a las políticas públicas que invierten en resciliencia en aras de la gobernabilidad. El vínculo, por tanto, es el componente integrado a la salud medioambiental, integrado a la posibilidad de enfrentar la adversidad de un medio muchas veces hostil y agresivo.

\section{d) Ser joven; sólo cuestión de identidades}

La juventud pareciera ser un producto más de la modernidad y sus procesos de industrialización y desarrollo económico. En ese sentido y coincidiendo con algunas miradas nos parece, en efecto, que la juventud es una construcción sociocultural «un fenómeno que dice algo del entramado de relaciones sociales que nos define una condición al interior de la comunidad donde vivimos». ${ }^{16}$ La diferenciación que produce lo juvenil está inscrita en tanto dinámica en la dialéctica modernidad-modernización, desde la aparición de la industrialización, la economía en tanto instrumento del capitalismo, lo político como práctica del poder, etc.; lo juvenil va apareciendo a propósito de la

15 Caleta Sur: «Signos de identidad». Revista Erial N¹. Santiago, Caleta Sur, 1998.

16 InJUV: «Introducción». Jóvenes, cultura juvenil y subjetividad en el Chile de los 90. Santiago, InJuv, 1999. 
necesidad de particularizar un proceso que va adquiriendo connotaciones propias y ganando en subjetividades, en lo que representa sin duda un aparecer tímido dado, fundamentalmente, por las condiciones económicas y laborales que el proceso de la modernidad va desatando.

Es decir, lo juvenil se sustenta como una necesidad de diferenciación frente a un proceso que se presenta como dual; por un lado, la tendencia homogeneizadora que ha significado expandir cada vez más las tendencias simbólicas frente a las cuales se elaboran las estrategias de inserción por ejemplo en el mercado, y por otro, las tendencias que diversifican y fragmentan cada vez más los juegos simbólicos de lenguajes, «la expansión incontenible del rock puede ser un buen ejemplo de las tendencias homogeneizantes experimentadas por los jóvenes chilenos en las últimas décadas. El surgimiento de las tribus urbanas, un buen ejemplo de la aparición de nuevos principios de diferenciación e identificación», ${ }^{17}$ donde el joven es a la vez producto y productor de cultura simbólica, referencia y autoreferencia de sus propias posibilidades y realidades, sujeto a las tendencias y las modas, pero también con la capacidad de incidir en ellas y de generar tendencias propias.

El ser joven está contenido en un contexto que ha tenido expresiones diversas según distintos momentos culturales. Por tanto, son los contextos particulares los cuales han ido incidiendo en que las juventudes sean de una determinada forma y no de otra. De acuerdo a ciertos parámetros más o menos claros, los ejes paradigmáticos de la modernidad han conducido a la juventud desde mano de obra industrial al auto-reconocimiento como particularidad en las jornadas de Mayo del 68 y de ahí a la instalación de temas que hasta el día de hoy son parte del sustrato de lo propiamente juvenil.

Los contextos se han ido forjando históricamente según los distintos procesos socio-históricos, los que finalmente han redundado en formulaciones y reformulaciones culturales que han sido las que han delineado a la juventud. Pero el ser joven se ha ido generando por procesos de intersubjetividad en una relación metacontextual, donde la autopercepción ha sido un proceso producido desde los distintos juegos metalingüísticos. Así el ser joven es un producto del entramado de la cultura, y es este entramado el que ha generado significaciones, sentidos, formas y expresiones distintas y diversas; en tanto, el ser joven, a su vez, ha estado condicionado por cuestiones de territoriali-

17 Idem. 
dad y cotidianeidad socioeconómica entre otros factores.

Asumimos este ser joven en tanto categoría metafísica, dado que nos parece a la vez que las formas y contenidos han ido variando según distintos momentos epocales y culturales. Existe cierto sustrato que ha permanecido, por así decirlo, inalterable en el sentido de cuestiones fundamentalmente reivindicativas que han sido permanentes en el transcurso del tiempo.

Pero todo esto sigue conduciéndonos hacia la pregunta fundamental que mueve este texto, ¿qué es ser joven?

Pareciera que el ser joven no responde meramente a una cuestión de índole etárea, sino más bien se construye a partir de una subjetividad, a partir del lugar que cada uno siente que ocupa en el mundo. Por eso la categoría de ser joven es más que una construcción objetivante, tiene que ver con desde dónde y cómo me paro en el mundo,

Ser joven es positivo y con altos y bajos también, como es la vida, muchas veces alegre, muchas veces con ganas de estar ahí en todas y a veces con malos ratos, con discusiones que van pasando, la idea es vivírsela yo creo, vivírsela, pero me siento optimista como joven porque igual se pueden hacer hartas cosas... ${ }^{18}$

No creer en nada simplemente, estar aburrida de todo lo que hay, estar aburrida de la música, de los libros, del sistema político, del sistema económico, un desencanto se podría decir... ${ }^{19}$

Las distintas formas de pararse en el mundo o frente a él van delineando las distintas percepciones y sensaciones que provoca esta idea del ser joven, no es un período estanco, formal y rígido; es más bien un producto de las distintas subjetividades que se van intercomunicando.

Si el ser joven aparece como un producto del entramado cultural y generado por la intersubjetividad, entonces el lugar en el mundo aparece como la ubicación geo-humana, el espacio de identidad que se ocupa en relación a y con otros. La categoría de identidad aparece como el componente que le da movilidad y dinamismo al período comprendido como juventud, dado que si el ser joven es producto de una intersubjetividad gestada en el entramado de la cultura, entonces la generación de identidad es ese lugar que se ocupa en el mundo, un

18 Entrevista Julio, 19 años, estudia, trabaja y participa en la Red Juvenil del Castillo, comuna de La Pintana, video «Juventudes», Santiago, Caleta Sur, 1999.

19 Entrevista Marcela: loc. cit. 
lugar que subjetiviza el estar, pero que también lo colectiviza, en tanto éste es necesariamente en relación con otro que ha forjado nociones, sentires y significaciones similares.

Para que exista lo que denominamos identidad debe necesariamente producirse una reflexión acerca de la autopercepción, de la construcción en relación al mundo, por eso la identidad es una cuestión relativa a la situación territorial, socio-espacial (como mapa mental), afectiva y económica.

Lo juvenil, a la vez que producto de la modernidad, es una situación coyuntural en ese gran proceso, coyuntural en tanto categoría, dado que la transitoriedad por la cual ha caminado el fenómeno de lo juvenil perfectamente puede verse alterado en una situación paradigmática diferente. Por tanto, si lo juvenil es producto de una gran y larga coyuntura llamada modernidad, también, lo es el ser adulto ya que éste es producto epocal de una autopercepción determinada.

La subjetividad e intercomunicación que se va generando en el decurso histórico genera una identidad que va rompiendo con la noción de causalidad lineal para ser asumida en tanto una simultaneidad que va delineando los momentos y las experiencias que constituyen el fenómeno todo de la vida, con las particularidades que la historia forja y los seres humanos van interpretando a la luz de los acontecimientos, dado que lo juvenil fundamentalmente acontece, se funda en el acto y en la acción, en una cotidianeidad que expresa significaciones y genera sentidos.

Pero esta fundación en el acto quiere decir también que el ser joven se hace presente en una relación de presencia con el objeto mundo, en una relación de constatación de la realidad como una cuestión que se funda con el acto, con el acto de reconocerme en tanto tal y de reconocer a otros, y la particularidad está dada por la imposibilidad de apreciar la integralidad, por la imposibilidad de mirar al objeto en su totalidad y poder desde ahí comprenderlo en forma definitiva y total.

\section{6. ÚLTIMAS Y NECESARIAS REFLEXIONES}

Entender el ser joven desde la perspectiva que hemos venido señalando implica, también, entender variados temas que están en relación con este fenómeno, pero también con el entramado cultural y humano en su integralidad. En este sentido, el tema de los derechos juveniles se funde con la mirada del respeto como una condición más 
esencial y que estaría a la base de lo propiamente humano. La enunciación de los derechos juveniles contenidos en el ámbito del respeto más amplio de las libertades humanas, pero sobre todo de las igualdades y de la solidaridad, es tratar de sustentar un proyecto basado en la conversión de la rabia y el dolor humano en solidaridad, es decir, sustentar una ética más amplia que la particularización de los derechos en cada período etáreo (derechos de los niños y las niñas, derechos de la mujer, derechos humanos, etc.); una ética que profundice en los aspectos de la fraternidad y de la igualdad tan olvidados por el proyecto emancipador de la modernidad. Esta noción más holística se confronta hoy día con la existencia de diversos juegos de lenguaje y la pluralidad de los juegos metacomunicacionales. En este sentido, los lineamientos teóricos de última data han adscrito a un relativismo metahistórica que anula cualquier posibilidad de la fraternidad y el encuentro colectivo.

Las salidas se pueden interpretar como la incertidumbre planteada por las construcciones culturales y epocales, entendiendo que parecieran ir conformándose ciertas corrientes que, de cualquier manera, se han ido gestando en forma subterránea. Como refiere Salazar, lo generacional se podría expresar en términos de la libertad y de la autonomía, una libertad que permite la identificación en relación con el dolor y con las vivencias de lo cotidiano y, por ende, una autonomía entendida no sólo como la posibilidad de ejercer presión vía reivindicación y demanda sino, la posibilidad de generar y levantar propuestas.

En síntesis, para someter a un análisis el ethos cultural de la sociedad moderna (marco valorativo que identifica, juzga y explica la conducta individual y social) y descubrir nuevos horizontes y perspectivas de transformación, debemos necesariamente, descubrir un pathos que sostenga y fundamente la necesidad real de un cambio desde la vida cotidiana.

El logos acentuó la necesidad de Eros y Pathos, amor y sentimiento, como valores fundantes para el contacto directo, de la intimidad y la afectividad, de la creatividad y la fantasía, de la simplicidad y la espontaneidad. La experiencia base de lo constitutivo de la humanidad del ser humano es la sentio ergo sum no el logos sino el pathos, la capacidad de ser afectados.

Se desprende de todo lo dicho hasta ahora, que la posibilidad de caracterizar aquel entramado de sentidos y significaciones llamado juventudes es, por lo menos una tarea que requiere - a nuestro juicio- la presencia y comprensión de todos los elementos que hemos 
venido señalando. Nos acecha la certeza que la caracterización que en este texto intentamos, es fundamentalmente un propósito, un camino posible, anhelante de certidumbres y, esencialmente, abierto al azar.

\section{ALGUNAS DISQUISICIONES FINALES}

Al finalizar esta reflexión, nos interesa arrojar algunas conclusiones de lo que ha sido este esfuerzo, así como enfatizar ciertas miradas. Destacar que éste ha sido un trabajo que habla de la dedicación y preocupación sobre los temas abordados que representan un constante objeto de reflexión para la experiencia del Programa Caleta Sur. Nos interesa destacar, también, que aun cuando en algunos capítulos y partes el texto aparezca con una carga teórica, ha sido la intención fundamental rescatar nuestra experiencia como Programa y que en conjunto hemos desarrollado con quienes compartimos todos estos años, en esa noción casi epistemológica del ser, hacer y estar con otros. En torno a las conclusiones podemos señalar las siguientes.

i) El texto constituye, en tanto cartografía histórico-cultural, una propuesta en sí misma, dado que planteamos una forma de entender el tema de lo juvenil como un fenómeno inscrito en un contexto histórico, cultural y social que es mayor que la especificidad del tema. Planteamos esto en torno a tres cuestiones esenciales que atraviesan el texto en forma transversal; por una parte la noción de crisis o agotamiento cultural, la ruptura con el paradigma dual cientificista, y la integralidad del ser joven como una cuestión que trasciende lo meramente etáreo y estructural.

ii) El ser joven está inscrito en una decursividad históricocultural y es parte de una coyuntura epocal llamada modernidad.

iii) La identidad de lo que es ser joven es una construcción intersubjetiva y metacomunicacional, es decir, ésta necesariamente, se construye en relación a otros y con otros.

iv) La noción de identidad del ser joven está inscrita en relación a una territorialidad, a una cartografía, definida por condiciones socioeconómicas, etáreas y políticas; desde ahí que aparezca como distinto ser un joven de La Pintana que ser un joven de Las Condes.

v) La idea de participación, entendida como protagonismo, es una construcción que se produce en una vivencialidad cotidiana, en una relación cara a cara, se funda en un acto de reconocerse y reconocer a otros, en una relación vinculante con el medio y con los otros.

vi) El decurso histórico-cultural ha dado cuenta de los proce- 
sos sociales acaecidos en la modernidad y puede, por tanto, fundarse una nueva noción de salida donde ésta no signifique la confrontación como única formulación válida frente a la diferencia.

vii) Las noción de juventudes planteada en este texto responde a la necesidad de romper el discurso homogeneizante acerca de la juventud como una construcción estancada y rígida, sin lugar a la diversidad de apuestas y de miradas.

En definitiva, para el Programa Caleta Sur, la perspectiva del trabajo comunitario - apuesta desde la cual se ha desarrollado la experiencia con los sectores juveniles - guarda estrecha relación con una propuesta de establecimiento y potenciación de dinámicas sociales orientadas a la recuperación de un sujeto social que asuma un rol protagónico en la transformación de las condiciones de vida, de ejercicio de ciudadanía plena, de una autonomía entendida como interdependencia y de generación de nuevas prácticas ético-culturales que otorguen un horizonte esperanzador y más humano. Desde esta perspectiva, la participación y organización comunitaria junto a la búsqueda de respuestas a las condiciones de vida que los actores vivencian, se transforman para la Caleta Sur en un imperativo categórico.

SANTIAGO (CHILE), DICIEMBRE DEL 2001 